\title{
A atuação da Univille no PET-Saúde/GraduaSUS
}

\author{
Patricia Esther Fendrich Magri, Mauren da Silva Salin, Helena Maria Antunes Paiano
}

\begin{abstract}
Resumo
O PET- Saúde/GraduaSUS é um programa federal que propõe a aproximação dos cursos da área da saúde com o SUS para reorientação da formação profissional em serviço. Em 2015, os cursos de Educação Física, Odontologia, Farmácia, Psicologia, Enfermagem e Medicina da Univille em parceria com a Secretaria de Saúde/Joinville-SC, elaboraram e conquistaram a aprovação do projeto, cuja meta é implantar um componente curricular comum aos seis cursos. Objetivo: descrever as ações realizadas no Projeto PET-Saúde/GraduaSUS. Metodologia: Desde a aprovação, uma equipe de professores e profissionais da Secretaria de Saúde trabalham arduamente desenvolvendo uma proposta de implementação de um componente curricular que compreenda a atenção à saúde como uma prática interprofissional. As ações desenvolvidas para alcançar a meta se referem a estudos teóricos para definição de concepções de formação e trabalho interprofissional, práticas colaborativas e clínica ampliada; reuniões com os coordenadores de cursos, tanto quanto uma prática considerada piloto, na qual estudantes de graduação, profissionais de saúde e professores da universidade experimentam a ideia principal da proposta que é estar nas Unidades Básicas de Saúde (UBS), em grupos, experimentando a educação interprofissional em benefício da formação para atuar na promoção da saúde dos usuários do SUS. O principal resultado é a implantação do componente obrigatório Práticas Interprofissionais em Saúde a partir de 2018 nos cursos de Educação Física e Odontologia. Os estudantes irão compor turmas mistas com atividades na universidade, nas UBS e realizarão diagnóstico da realidade, planejamento e intervenções sob a supervisão de professores e preceptores. Conclusão: Embora se reconheça que o trabalho em equipe exige persistência e vontade de inovar, a meta do projeto está em processo de consolidação. Durante a caminhada muitos obstáculos tiveram que ser transpostos, porém com determinação, foco e liderança o componente está consolidado e no próximo ano poderemos relatar os resultados do componente.
\end{abstract}

Descritores: Educação, Formação, Saúde, Equipes 